\title{
Biological and molecular characterization of feline caliciviruses isolated from cats in South Korea
}

\author{
Dong-Kun Yang ${ }^{1, *}$, Yu-Ri Park ${ }^{1}$, Jae Young Yoo ${ }^{1}$, Sung-Suk Choi ${ }^{1}$, Yeseul Park ${ }^{1}$, Sungjun An ${ }^{1}$, Jungwon Park ${ }^{2}$, \\ Heui-Jin Kim², Jongho Kim², Ha-Hyun Kim', Bang-Hun Hyun ${ }^{1}$ \\ ${ }^{1}$ Viral Disease Research Division, Animal and Plant Quarantine Agency, Ministry of Agriculture, Food and Rural Affairs, \\ Gimcheon 39660, Korea \\ ${ }^{2}$ Animal Disease Diagnostic Division, Animal and Plant Quarantine Agency, Ministry of Agriculture, Food and Rural Affairs, \\ Gimcheon 39660, Korea
}

\begin{abstract}
Feline calicivirus (FCV) infection results in a common upper respiratory disease associated with oral ulceration in cats. Although FCV infection has been reported in cats worldwide, the biologic and genetic features of South Korean FCV are unclear. We aimed to investigate the biological and genetic features of South Korean FCV isolates. Crandell-Rees feline kidney (CRFK) cells were used to isolate FCV from 58 organ homogenate samples. The FCV isolates were confirmed by cytopathic effects, immunofluorescence, electron microscopy, and reverse transcription polymerase chain reaction assays. Viral genetic analysis was carried out with VP2 gene and complete genomes of FCVs. Five viruses propagated in CRFK cells were confirmed to be FCVs. The FCV17D283 isolate showed the highest viral titer of $10^{7.2} \mathrm{TCID}_{50} / \mathrm{mL}$ at $36 \mathrm{~h}$ post-inoculation. Korean FCV isolates did not grow well in Vero, BHK-21, A72, or Madin-Darby canine kidney cells. The FCV17D03 and FCV17D283 isolates had the highest genetic similarity (80.1\% and 86.9\%) with the UTCVM-H1 and 14Q315 strains, which were isolated in the United States and South Korea in 1995 and 2014 , respectively. We isolated five FCVs from cats and detected important genetic differences among them. FCV isolates did not show any virulent effects in mice.
\end{abstract}

Keywords: feline calicivirus, diagnosis, phylogenetic analysis

*Corresponding author

Dong-Kun Yang

Viral Disease Research Division, Animal and Plant Quarantine Agency, Ministry of

Agriculture, Food and Rural Affairs, 177

Hyeoksin 8-ro, Gimcheon 39660, Korea

Tel: +82-54-912-0785

Fax: +82-54-912-0812

E-mail: yangdk@korea.kr

ORCID

Dong-Kun Yang

https://orcid.org/0000-0001-5765-3043

Yu-Ri Park

https://orcid.org/0000-0002-2829-4368

Jae Young Yoo

https://orcid.org/0000-0001-7119-5421

Sung-Suk Choi

https://orcid.org/0000-0001-5124-9736

Yeseul Park

https://orcid.org/0000-0001-9168-1064

Sungjun An

https://orcid.org/0000-0001-8815-9478

Jungwon Park

https://orcid.org/0000-0002-2546-9732

Heui-Jin Kim

https://orcid.org/0000-0003-2577-1488

Jongho Kim

https://orcid.org/0000-0002-3719-860X

Ha-Hyun Kim

https://orcid.org/0000-0001-6473-0035

Bang-Hun Hyun

https://orcid.org/0000-0002-3429-3425

Conflict of Interest

The authors declare no conflicts of interest.

Received: July 29, 2020

Revise d: September 16, 2020

Accepted: September 24, 2020

\section{Introduction}

Feline calicivirus (FCV) belongs to the genus Vesivirus in the family Caliciviridae. The FCV genome has approximately 73,000 nucleotides in four open reading frames (ORFs) [1]. The first ORF (ORF1) encodes a 200-kDa polyprotein that is processed into six non-structural proteins-p5.6, p32, p39, p30, VPg, and Pro-pol. The p39 protein suppresses the host innate immune response [2]. The second ORF (ORF2) encodes the mature capsid protein VP1, which is divided into the N-terminal arm, shell domain, and protruding domain; overall, it comprises six regions (A to F) [3]. ORF3 encodes the minor structural protein VP2 and is implicated in the production of infectious virus. ORF4 is assumed to be a frameshift of the VP1 region and its function is unknown [4].

FCV is highly contagious; it is usually transmitted via the oronasal route and ocular discharge from infected cats [5]. FCV strains have been detected in members of the Felidae family and in dog feces in several countries [6-8]. Based on clinical symptoms, two types of FCV infection-classic and virulent systemic disease (VSD)-have been reported in cats under 1 year of age. The clinical signs of classic FCV infection in cats are fever, nasal and ocular discharge, oral ulceration, and conjunctivitis. In some instances, FCV infections lead to severe pneumonia and sudden death. VSD caused by FCV has been reported in several countries and manifests as pyrexia, cutaneous edema, ulcerative dermatitis, anorexia, and jaundice; it has a $\sim 50 \%$ mortality rate $[9,10]$. Method for diagnosis of FCV infection includes virus isolation, immunofluorescence, and reverse transcriptase-polymerase chain reaction (RTPCR) assays [11,12]. Although FCV infections were observed in South Korean cats from 2015 to 2017 [13], their isolation and genetic variation have 
not been reported. In this study, we investigated biological and molecular characterization of five FCV isolates obtained from 58 organ homogenate samples of 22 cats using CrandellRees feline kidney (CRFK) cells.

\section{Materials and Methods}

\section{Samples}

In total, 58 samples including lung (5), spleen (6), brain (5), kidney (4), liver (4), heart (3), intestine (10) and feces (21) from 22 cats sent to the Animal and Plant Quarantine Agency (APQA), South Korea were analyzed in this study. The samples obtained from 2017 to 2019 were subjected to virus isolation. Each sample was placed in a mortar and a $10 \%$ homogenate was produced in Dulbecco's modified Eagle's medium. Tissue debris was removed by centrifugation at $2,500 \times \mathrm{g}$ for $15 \mathrm{~min}$ and the samples were passed through a $0.45-\mu \mathrm{m}$ syringe filter.

\section{Virus isolation, growth kinetics, and titration}

The CRFK (ATCC, CCL-94) cells used for virus isolation were cultured in Dulbecco's modified Eagle's medium supplemented with penicillin, streptomycin, amphotericin B, and $10 \%$ fetal bovine serum (FBS; Gibco BRL). Confluent CRFK cells in 24-well plates were washed twice with phosphate-buffered saline (PBS, pH 7.2) and inoculated with 200 $\mu \mathrm{L}$ of sample. After cells had been incubated at $37^{\circ} \mathrm{C}$ for $1 \mathrm{~h}$, the samples were removed and $1 \mathrm{~mL}$ of fresh Dulbecco's modified Eagle's medium containing 3\% FBS was added to each well. The plates were placed in a $5 \% \mathrm{CO}_{2}$ incubator at $37^{\circ} \mathrm{C}$ for 5 days. The supernatant of cells that exhibited cytopathic effects (CPEs) was harvested and inoculated onto fresh CRFK cells for a second passage. If no CPEs were observed after 5 days, the samples were considered virus-negative.

The growth kinetics of FCV isolates were evaluated. Briefly, CRFK cells grown in $25-\mathrm{cm}^{2}$ flasks were inoculated with isolates $\left(100 \mathrm{TCID}_{50} / \mathrm{mL}\right)$ and harvested at 12 -h intervals for $72 \mathrm{~h}$. After three continuous freeze-thaw cycles had been performed, the viral titers were determined based on the presence of CPEs according to the Spearman-Karber method and expressed as $\mathrm{TCID}_{50} / \mathrm{mL}$. To identify optimal cells for viral propagation, the two isolates were inoculated onto the following six cell lines in $25-\mathrm{cm}^{2}$ flasks: CRFK, Fcwf-4 (ATCC, CRL2728), BHK-21 (ATCC, CCL-10), A72 (ATCC, CRL-1542), Madin-Darby canine kidney (MDCK; ATCC, CCL-34), and Vero (ATCC, CCL81). After cells had been incubated for 2 days, the flasks were subjected to three freezethaw cycles and centrifuged as described above. The viral titers of the centrifuged solutions were then determined as described above.

\section{Immunofluorescence assay}

CRFK cells infected with the five isolates in 96-well plates were fixed with $80 \%$ acetone at $-20^{\circ} \mathrm{C}$ for $15 \mathrm{~min}$. After cells had been washed with PBS three times, they were reacted with a mouse anti-FCV antibody (Abcam, USA) at $37^{\circ} \mathrm{C}$ for $1 \mathrm{~h}$ and then with a fluorescein isothiocyanate-conjugated goat anti-mouse $\operatorname{IgG}+\operatorname{IgM}$ antibody (1:200 dilution; KPL Laboratories, USA). After plates had been washed with PBS, the CRFK cells were examined under a fluorescence microscope at $200 \times$ magnification (TE2000-U, Nikon Instruments Inc., Japan). CRFK cells that exhibited CPEs and cytoplasmic fluorescence were considered to be infected with FCV.

\section{Electron microscopy}

FCV isolates propagated in CRFK cells were concentrated with polyethylene glycol-8000 (Sigma) and purified. CRFK cells infected with FCV isolate were harvested at $48 \mathrm{~h}$ postinoculation (PI) and subjected to three freeze-thaw cycles. The polyethylene glycol-precipitated pellets were dissolved in TNE buffer (100 mM Tris- $\mathrm{HCl}, 100 \mathrm{mM} \mathrm{NaCl}$, and $1 \mathrm{mM}$ EDTA; $\mathrm{pH} 7.6$ ) at $5 \%$ of the original volume. Two samples were placed atop the $20 \%$ sucrose layer in a centrifuge tube and centrifuged at $100,000 \times \mathrm{g}$ for $120 \mathrm{~min}$. The clear band between the $30 \%$ and $40 \%$ sucrose layers was transferred to a dialysis cassette and dialyzed overnight against PBS to remove residual sucrose solution. The dialyzed samples were placed into Vivaspin tubes (Sartorius, Göttingen, Germany) and centrifuged at $3,500 \times \mathrm{g}$ for $15 \mathrm{~min}$; the supernatants were then collected. For multiple samples, a drop of concentrated, purified virus suspension was placed on a Formvarcoated grid and negatively stained with $1 \%$ uranyl acetate.

To identify virus particles, CRFK cells were inoculated with FCV isolates. At $48 \mathrm{~h}$ PI, the cells were harvested and fixed with $2.5 \%$ glutaraldehyde and $1 \%$ osmium tetroxide in PBS. The fixed cells were embedded in resin, cut into thin sections using a microtome, and stained with uranyl acetate and lead citrate. The FCV isolate sections and viral suspensions on grids were examined under a model 7100 electron microscope (Hitachi, Japan).

\section{RT-PCR and sequencing}

Viral RNA was extracted using an RNA extraction kit (Bioneer, Korea), in accordance with the manufacturer's instructions. RNA was eluted with $50 \mu \mathrm{L}$ of elution buffer. RT-PCR was carried out with the One-Step RT-PCR Kit, using a primer set for the partial VP2 gene (Table 1). For RTPCR, $5 \mu \mathrm{L}$ of denatured RNA, $1 \mu \mathrm{L}$ of each primer (50 pmol), and $43 \mu \mathrm{L}$ of distilled water were added to AccuPower $^{\circledR}$ RT-PCR PreMix (Bioneer). The RT-PCR reaction consisted of cDNA synthesis at $50^{\circ} \mathrm{C}$ for $30 \mathrm{~min}$; 35 cycles of denaturation, annealing, and extension $\left(94^{\circ} \mathrm{C}\right.$ for $30 \mathrm{~s}, 54^{\circ} \mathrm{C}$ for $30 \mathrm{~s}$, and $72^{\circ} \mathrm{C}$ for $40 \mathrm{~s}$, respectively); and a final extension at $72^{\circ} \mathrm{C}$ for $10 \mathrm{~min}$. RT-PCR products were confirmed by electrophoresis in a $2.0 \%$ agarose gel containing Redsafe ${ }^{\mathrm{TM}}$ Nucleic Acid Staining Solution (iNtRON, Korea).

The RT-PCR products were purified using a gel extraction kit and ligated into the $\mathrm{pGEM}^{\circledR}-\mathrm{T}$ Easy Vector (Promega, USA), in accordance with the manufacturer's instructions. Plasmid DNA was extracted from six Escherichia coli 
Table 1. Primers used for amplification of the partial ORF3 gene from feline calicivirus

\begin{tabular}{lccc}
\hline \hline Name & Oligonucleotide sequence (5'-3') & Target gene & Size (bp) \\
\hline FCVDF1 & GAGGCGCTCCTACATGGGAATWC & \multirow{2}{*}{ VP2 } & 259 \\
FCVDR1 & ACAWGGCCWTGTACCCTYTGCTCAAG & & \\
\hline
\end{tabular}

W: A or T, Y: C or T.

(DH5 $\alpha$ ) colonies; PCR product insertions were verified by digestion with EcoRI (Bioneer). Two plasmids per gene were submitted to Macrogen Inc. (Korea) for sequencing using the MJ Research PTC-225 Peltier Thermal Cycler, ABI Prism BigDye $^{\mathrm{TM}}$ Terminator Cycle Sequencing Kit, and AmpliTaq $^{\text {TM }}$ DNA polymerase (FS enzyme; Applied Biosystems, USA). Single-pass sequencing was performed using the SP6 and T7 universal primer sets. Partial VP2 nucleotide sequences were thus determined.

Complete-genome sequencing and phylogenetic analysis Viral RNAs extracted from FCV isolates were sent to Macrogen. Their complete genomes were sequenced by a nextgeneration sequencing technique. The full VP1 gene sequences (approximately $2010 \mathrm{bp}$ ) were compared with those of the FCV reference strains.

Two phylogenetic trees were constructed by the neighborjoining method using MEGA v. 7.0.20 software (http://www. megasoftware.net) based on the partial VP2 and full VP1 genes from five or two FCV isolates and other FCV strains from the GenBank database. A bootstrap method with 1,000 replicates was used to verify the reliability of the phylogenetic trees.

\section{Mouse inoculation assay}

A mouse experiment was performed at the APQA in South Korea, in accordance with a protocol approved by the Experimental Animal Ethics Committee (approval number: 2020-
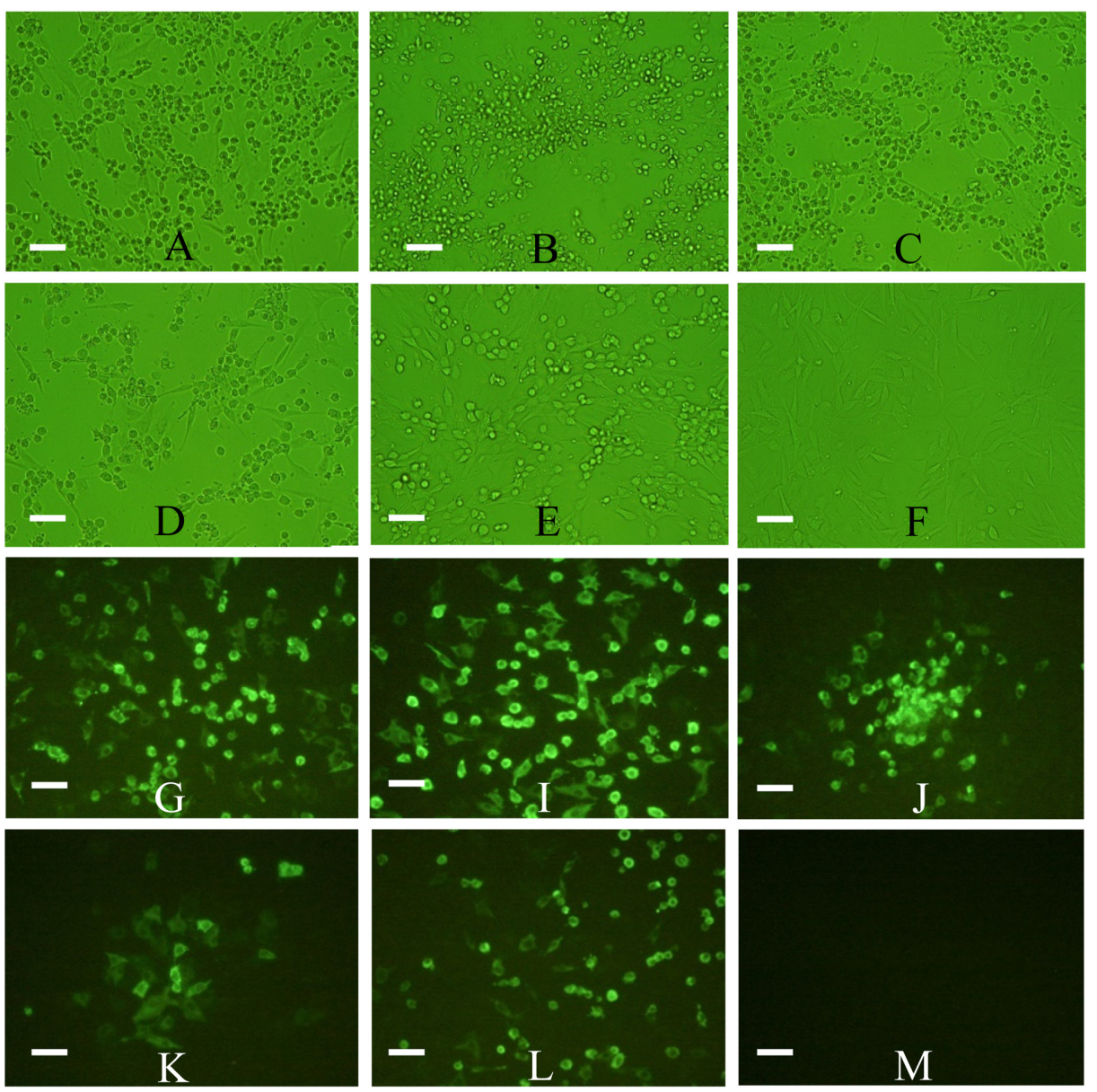

Fig. 1. Identification of FCV based on CPEs and fluorescence assay results. CPEs in CRFK cells infected with FCV17D03 (A), FCV17D62 (B), FCV17D281 (C), FCV17D283 (D), and FCV19D115 (E). Cytoplasmic fluorescence in CRFK cells infected with FCV17D03 (G), FCV17D62 (I), FCV17D281 (J), FCV17D283 (K), and FCV19D115 (L), as well as in normal CRFK cells (F and M). Scale bars, $100 \mathrm{~nm}$. FCV, feline calicivirus; CPE, cytopathic effect; CRFK, Crandell-Rees feline kidney. 
431). To evaluate the virulence of the FCV isolates, 18 6week-old ICR mice (OrientBio, Korea) were divided into three groups. Two groups of six mice each were peritoneally inoculated with $10^{7.0} \mathrm{TCID}_{50} / \mathrm{mL}$ of FCV isolates. The third group served as the control. The mice were observed for clinical signs, including depression and loss of body weight, for 14 days.

\section{Results}

Isolation and biological characterization of FCV isolates

Of the 58 organ samples, five generated CPEs, characterized by detachment and destruction of infected cells (Fig. 1). Five virus isolates from 4 feces and one lung samples were designated FCV17D03, FCV17D62, FCV17D281, FCV17D283, and FCV19D115. CRFK cells infected with the five FCV isolates were fixed in cold acetone and stained with mouse monoclonal antibodies against FCV. Fluorescence was observed in the cytoplasm of CRFK cells (Fig. 1G to L), confirming that the isolates were FCV.

The growth kinetics of two of the five FCV isolates were evaluated. The FCV17D283 isolate harvested at $36 \mathrm{~h}$ PI exhibited the highest viral titer $\left(10^{7.2} \mathrm{TCID}_{50} / \mathrm{mL}\right)$ (Fig. 2$)$. At $18 \mathrm{~h} \mathrm{PI}, 70 \%$ of CRFK cells infected with FCV isolates exhibited CPEs. Based on FCV growth kinetics, virus antigen was harvested at $36 \mathrm{~h}$ PI for electron microscopy. The FCV isolates were inoculated into CRFK, Fcwf-4, BHK-21, A72, Vero, and MDCK cells (derived from cat kidney, cat fetus organ, hamster kidney, dog unknown tumor, monkey kidney, and dog kidney, respectively). CRFK cells infected with FCV showed the highest titer of $10^{7.65} \mathrm{TCID}_{50} / \mathrm{mL}$. In contrast, BHK-21, A72, Vero, and MDCK cells did not exhibit CPEs; all demonstrated viral titers of $0 \mathrm{TCID}_{50} / \mathrm{mL}$
(Fig. 2B). Therefore, cat-derived cells were suitable for isolation of FCV.

FCV17D03 and FCV17D283 virus particles purified by sucrose density gradient ultracentrifugation from infected CRFK cells were identified by EM. The viral particles were spherical and $30-40 \mathrm{~nm}$ in diameter, a morphology typical of Caliciviridae (Fig. 3A and B). Large numbers of calicivirus
A

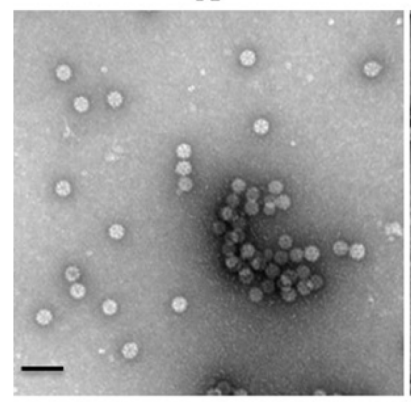

$\mathrm{C}$

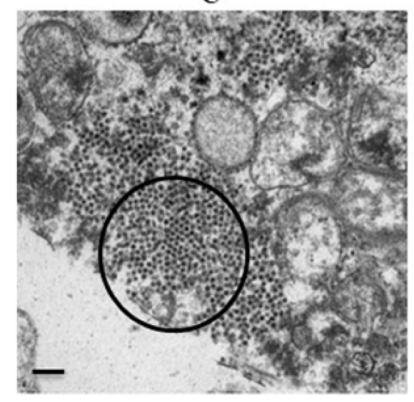

B

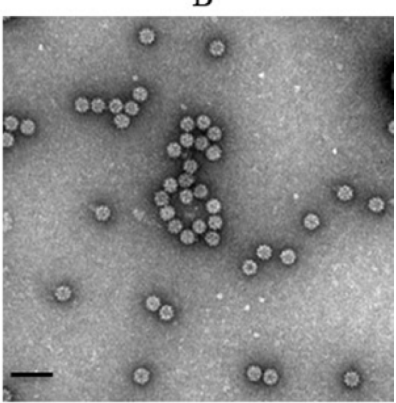

$\mathrm{D}$

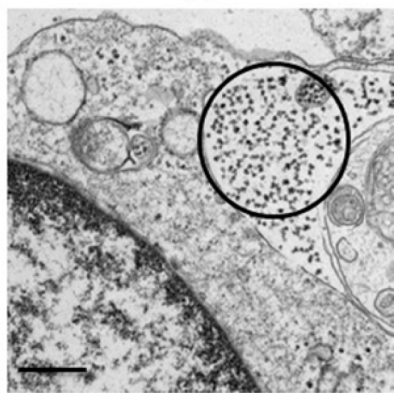

Fig. 3. Transmission electron micrographs of purified FCV17D03 (A) and FCV17D283 (B), and CRFK cells infected with FCV17D03 (C) or FCV17D283 (D). Scale bars, $100 \mathrm{~nm}$ $(\mathrm{A}, \mathrm{B}, \mathrm{C})$ and $500 \mathrm{~nm}$ (D). Circles indicate virus particles in the cytoplasm of CRFK cells. FCV, feline calicivirus; CRFK, Crandell-Rees feline kidney.

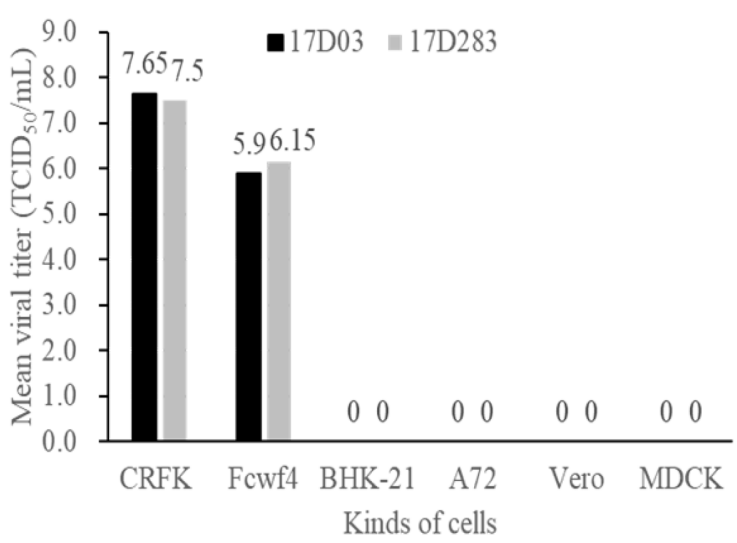

B

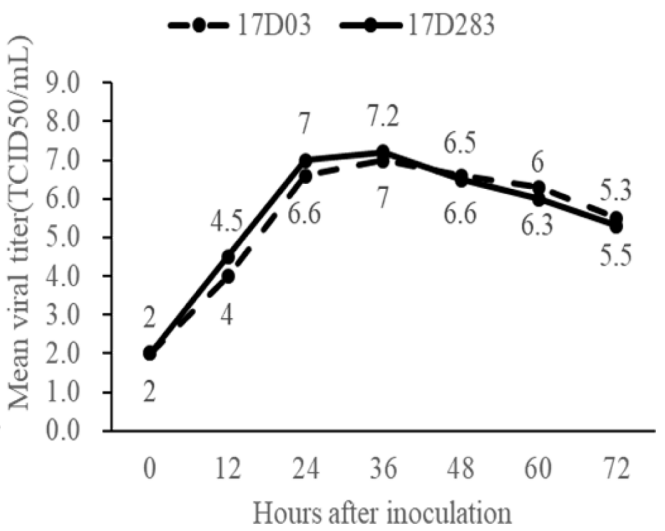

Fig. 2. Titers of FCV isolates in six cell lines to assess cell tropism (A) and growth kinetics in CRFK cells (B). FCV FCV17D03 and FCV17D283 showed the highest titers of $10^{7.2}$ and $10^{7.0} \mathrm{TCID}_{50} / \mathrm{mL}$ in CRFK cells at $36 \mathrm{~h}$ post-inoculation, respectively, but did not grow in BHK-21, A72, Vero, or MDCK cells. CRFK, Crandell-Rees feline kidney; MDCK, Madin-Darby canine kidney; FCV, feline calicivirus. 
particles were observed in the cytoplasm of CRFK cells (Fig. $3 \mathrm{C}$ and $\mathrm{D})$.

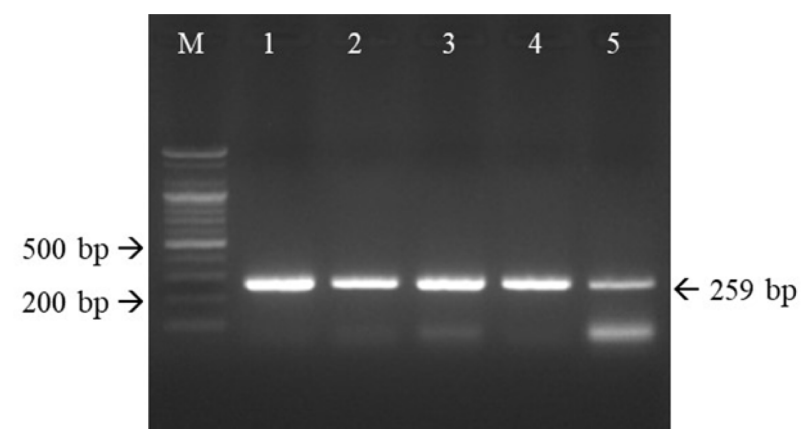

Fig. 4. RT-PCR products of the expected sizes (259 bp) confirmed that the five isolates were FCVs. Primers targeting FCV VP2 were used for RT-PCR. M, 1 kb ladder; lane 1, FCV17D03; lane 2, FCV17D62; lane 3, FCV17D281; lane 4, FCV17D283; lane 5, FCV19D115. RT-PCR, reverse transcriptase-polymerase chain reaction; FCV, feline calicivirus.

\section{Genetic characterization of five FCV isolates}

The RT-PCR products of the five FCV isolates were cloned into vectors. The PCR products of the five isolates were $259 \mathrm{bp}$ in length, which confirmed that they were FCV (Fig. 4).

Comparative analysis of 259 nucleotides of the VP2 genes from the five FCV isolates revealed sequence homologies of $79.2 \%$ to $99.2 \%$ (Fig. 5). The FCV17D283 isolate was closely related to the FCV19D115 isolate (99.2\% homology). The VP1 amino acid sequences from two FCV isolates were aligned with the corresponding sequence from the F9 strain used in an FCV vaccine in Japan. The VP1 genes from the FCV17D03 and FCV17D283 isolates were composed of 2,007 and 2,010 nucleotides encoding 668 and 671 amino acids, respectively (Fig. 6). The FCV17D03 isolate had a three-amino-acid deletion at positions 493 to 495 ; there were 4 or 5 potential N-linked glycosylation sites in FCV17D283 and FCV17D03. The VP1 gene from FCV17D03 demonstrated nucleotide and amino acid homologies of $75.8 \%$ and $84.7 \%$ with the corresponding sequences from FCV17D283 (data not shown). Based on the VP1 phylogenetic tree,

A

\begin{tabular}{rcccccc}
\hline & \multicolumn{5}{c}{ Homology of nucleotide sequence among five Korean FCV } \\
\cline { 2 - 7 } Isolate & FCV17D03 & FCV17D62 & FCV17D281 & FCV17D283 & FCV19D115 \\
\hline FCV17D03 & & 79.2 & 80.7 & 79.5 & 79.9 \\
Fivergence & FCV17D62 & 24.7 & & 81.9 & 79.9 & 79.2 \\
& FCV17D283 & 22.7 & 21 & & 80.3 & 80.7 \\
FCV19D115 & 24.3 & 23.5 & 23.1 & & 99.2 \\
\hline
\end{tabular}

B

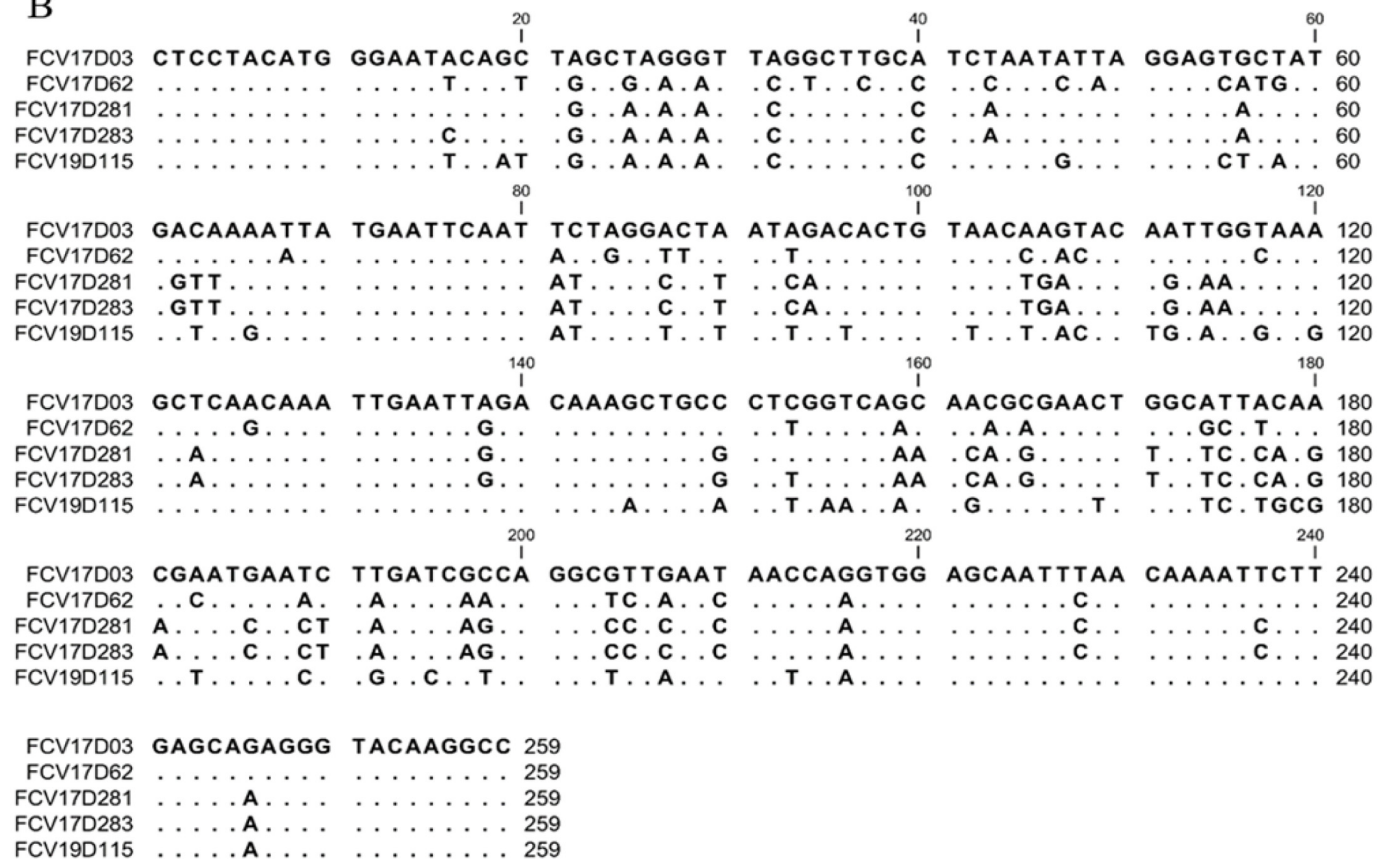

Fig. 5. Nucleotide sequence homology of FCV17D03, FCV17D62, FCV17D281, FCV17D283, and FCV19D115 (A) and alignment of the VP2 genes from five FCV isolates (B). FCV, feline calicivirus. 


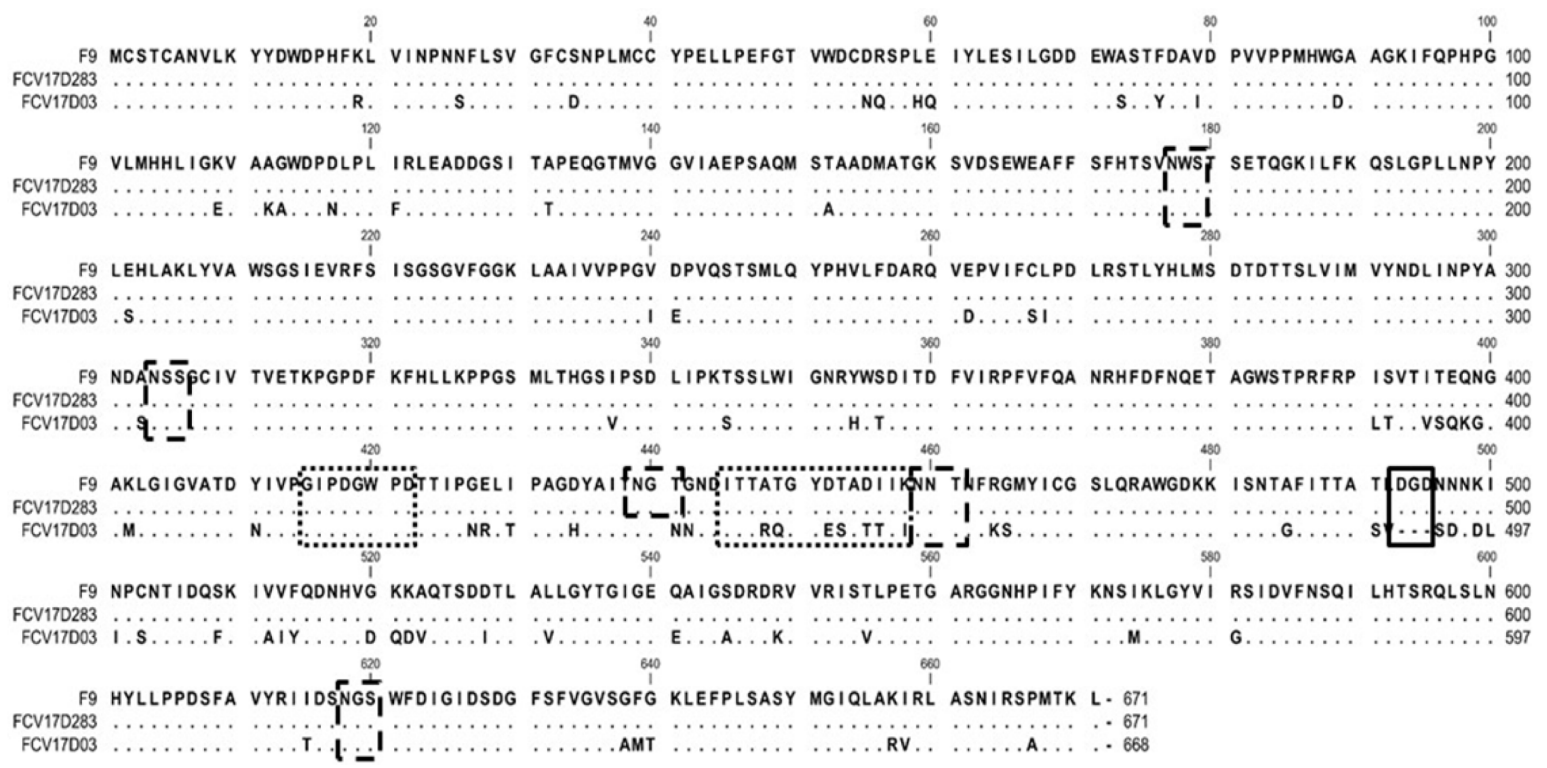

Fig. 6. VP1 amino acid sequence alignment of FCV17D283, FCV17D03, and FCV F9. FCV17D03 exhibited a three-amino-acid deletion at positions 493 to 495 (box with thick line). Two linear epitopes are indicated by boxes with thin dotted lines. Five potential $\mathrm{N}$-linked glycosylation sites (N-X-S/T) are indicated by boxes with thick dotted lines. FCV, feline calicivirus.

A

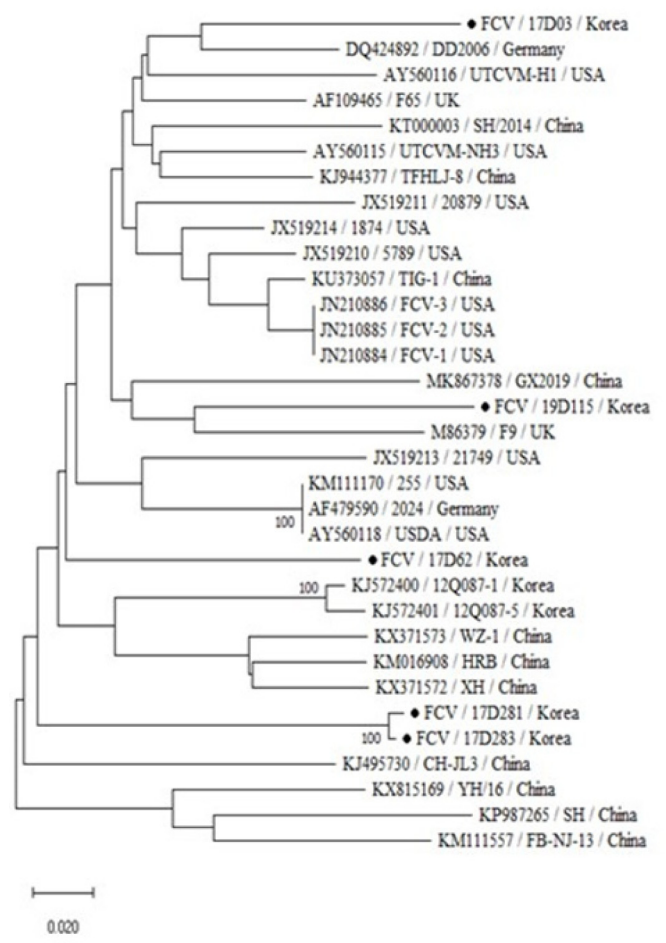

B

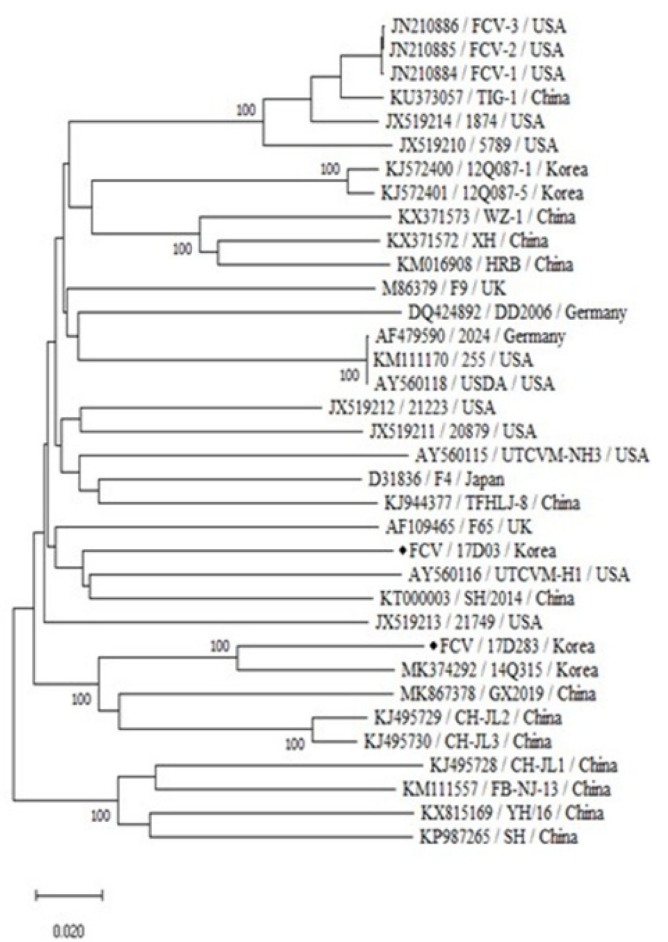

Fig. 7. Phylogenetic analysis based on partial VP2 (A) and complete VP1 (B) nucleotide sequences from 31 FCV strains. FCV17D03 and FCV17D283 were closely related to FCV UTCVM-H1 (isolated in the United States in 1995) and 14Q315 (isolated in South Korea in 2014), respectively. Phylogenetic trees were constructed from nucleotide sequences by the neighbor-joining method. FCV, feline calicivirus.

FCV17D03 and FCV17D283 showed respective homologies of $80.1 \%$ and $86.9 \%$ with UTCVM-H1 (reported in the United States) and 14Q315 (reported in South Korea) (Fig. 7).

\section{Virulence in mice}

Six 6-week-old ICR mice were inoculated with FCV17D03 or FCV17D283 at a titer of $10^{7.0} \mathrm{TCID}_{50} / \mathrm{mL}$ to assess viru- 


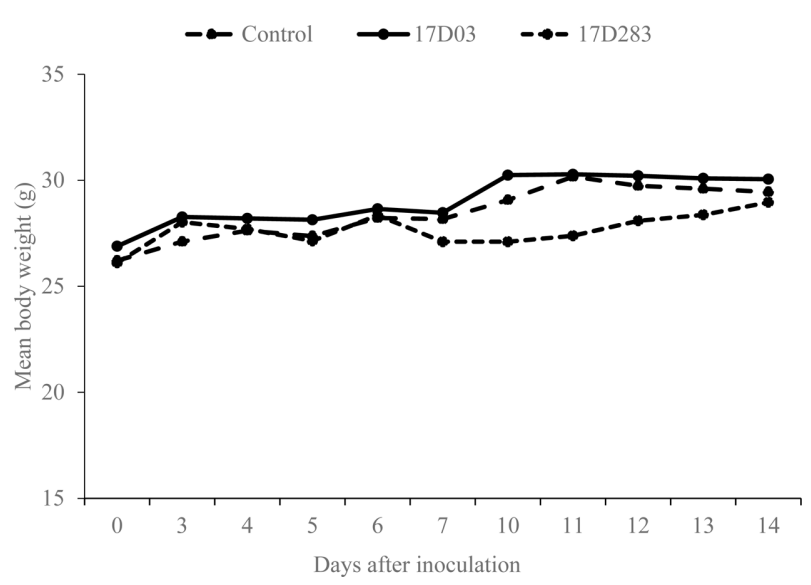

Fig. 8. Body weights of ICR mice inoculated intraperitoneally with FCV17D03 and FCV17D283. There were no losses of body weight during the 14-day study period. FCV, feline calicivirus.

lence. None of the mice showed clinical signs or considerable weight change during the observation period (Fig. 8).

\section{Discussion}

FCV is a common viral pathogen that causes upper respiratory tract disease in cats $[6,7]$. FCV infections have been reported in members of the Felidae family, such as domestic cats, lions, tigers, and cheetahs; FCV has also been observed in dog feces $[8,9,14,15]$. Although cats of all ages are susceptible to FCV, adult cats with FCV-associated VSD have a $\sim 50 \%$ mortality rate, raising doubt regarding the efficacy of the FCV vaccine $[9,16]$. Because it is difficult to confirm a diagnosis of FCV infection based on clinical symptoms, there have been few reports regarding the prevalence of FCV in Korean cats [13]. Here, we attempted to isolate FCV from 58 samples of 22 dead cats. The isolates were confirmed to be FCV based on the presence of CPEs, as well as the results of immunofluorescence and RT-PCR assays.

Feline-origin cells (CRFK and Fcwf4 cells) were susceptible to FCV, whereas non-feline cells (BHK-21, A72, Vero, and MDCK cells) were not. CRFK cells were the most suitable cell type for FCV isolation, suggesting that they express the FCV receptor feline junctional adhesion molecule 1 [17]. We evaluated the characteristics of FCV17D03 and FCV17D283; their titers reached $10^{7.0}$ to $10^{7.2} \mathrm{TCID}_{50} / \mathrm{mL}$ at 36 h PI, similar to the TIG-1 and 2280 strains from China [7]. Therefore, our FCV isolates are presumably wild-type viruses circulating in cats. Electron microscopy analysis of the two FCV isolates revealed a morphology typical of FCV; FCV17D03 and FCV17D283 virus particles were of similar size and shape to caliciviruses isolated from domestic cats in China [6,13]. RT-PCR-related methods such as real-time and nested PCR have been used to detect FCV $[11,12]$. RT-PCR amplification of the VP2 genes from FCV isolates yielded bands of the expected size of $259 \mathrm{bp}$, confirming that the iso- lates were FCV.

Nucleotide sequence analysis has not demonstrated distinct clustering of FCV strains according to geography or disease [18]; our results were similar to those of prior studies. Alignment of the partial nucleotide sequences of VP2 from five FCV isolates showed similarities of 79.2\% (FCV17D03, FCV17D62, and FCV19D115) to 99.2\% (FCV17D283 and FCV19D115). Phylogenetic analysis of the FCV VP1 gene has been performed to assess evolutionary relationships and genetic variation among FCVs [19]. The sequences of VP1 from two South Korean FCV isolates were considerably different $(75.8 \%$ and $76.6 \%$, respectively) from the corresponding sequence in the FCV vaccine strain, F9. These results are similar to previously reported findings $[14,20]$. Failure of the FCV vaccine in cats is reportedly related to genetic variation of the VP1 protein and use of a single vaccine strain [17,21]. The considerable sequence variation among South Korean FCV isolates suggest that FCV vaccines should be reevaluated.

Differences in receptor interaction, post-binding events, and conformation have been proposed to explain the two clinical manifestations of FCV infection-classical and VSD [22]. A VP1 amino acid sequence alignment involving the FCV17D03 and FCV17D283 isolates and the F9 strain indicated a three-amino-acid deletion at positions 493 to 495 in FCV17D03. The two Korean FCV isolates with altered VP1 will be useful for veterinary medicine research. The isolation of FCVs from naturally infected cats will also facilitate the development of diagnostics and FCV vaccines. Therefore, further studies are needed regarding the virulence of FCVs in cats.

Two Korean FCVs did not cause symptoms in 6-week-old mice following intraperitoneal inoculation, indicating that mice cannot be used to evaluate FCV virulence. However, because we did not assess the pathogenicity of the two FCV isolates in cat, further studies of their virulence and immunogenicities are needed in cats.

In conclusion, we isolated and confirmed five FCVs from naturally infected cats using CRFK cells. FCV17D03 and FCV17D283 were closely related to FCV UTCVM-H1 and 14Q315. CRFK cells were the most suitable for isolation of FCV. FCV17D03 and FCV17D283 may enable the development of an FCV vaccine and diagnostic reagents, as well as viricidal testing of disinfectants. Finally, the FCV VP1 sequence data will provide a useful reference for future research.

\section{Acknowledgments}

This study was supported financially by a grant (B1543083-2020-22-01) from the Animal and Plant Quarantine Agency, Ministry of Agriculture, Food and Rural Affairs (MAFRA), Korea.

\section{References}

1. Di Martino B, Marsilio F, Roy P. Assembly of feline 
calicivirus-like particle and its immunogenicity. Vet Microbiol 2007;120:173-178.

2. Yumiketa $Y$, Narita T, Inoue Y, Sato G, Kamitani W, Oka T, Katayama K, Sakaguchi T, Tohya Y. Nonstructural protein p39 of feline calicivirus suppresses host innate immune response by preventing IRF-3 activation. Vet Microbiol 2016; 185:62-67.

3. Bhella D, Gatherer D, Chaudhry Y, Pink R, Goodfellow IG. Structural insights into calicivirus attachment and uncoating. $\mathrm{J}$ Virol 2008;82:8051-8058.

4. Bhella D, Goodfellow IG. The cryo-electron microscopy structure of feline calicivirus bound to junctional adhesion molecule $\mathrm{A}$ at 9-angstrom resolution reveals receptor-induced flexibility and two distinct conformational changes in the capsid protein VP1. J Virol 2011;85:11381-11390.

5. Radford AD, Addie D, Belák S, Boucraut-Baralon C, Egberink H, Frymus T, Gruffydd-Jones T, Hartmann K, Hosie MJ, Lloret A, Lutz H, Marsilio F, Pennisi MG, Thiry E, Truyen U, Horzinek MC. Feline calicivirus infection. $\mathrm{ABCD}$ guidelines on prevention and management. J Feline Med Surg 2009;11:556-564.

6. Zhao Y, Chen X, Ying Y, Wang K, Dong H, Gao C, Yang $\mathrm{S}, \mathrm{Hu}$ G. Isolation and phylogenetic analysis of three feline calicivirus strains from domestic cats in Jilin Province, China. Arch Virol 2017;162:2579-2589.

7. Tian J, Liu D, Liu Y, Wu H, Jiang Y, Zu S, Liu C, Sun X, Liu J, Qu L. Molecular characterization of a feline calicivirus isolated from tiger and its pathogenesis in cats. Vet Microbiol 2016;192:110-117.

8. Gabriel SS, Tohya Y, Mochizuki M. Isolation of a calicivirus antigenically related to feline caliciviruses from feces of a dog with diarrhea. J Vet Med Sci 1996;58:1041-1043.

9. Coyne KP, Jones BR, Kipar A, Chantrey J, Porter CJ, Barber PJ, Dawson S, Gaskell RM, Radford AD. Lethal outbreak of disease associated with feline calicivirus infection in cats. Vet Rec 2006;158:544-550.

10. Radford AD, Coyne KP, Dawson S, Porter CJ, Gaskell RM. Feline calicivirus. Vet Res 2007;38:319-335.

11. Marsilio F, Di Martino B, Decaro N, Buonavoglia C. A novel nested PCR for the diagnosis of calicivirus infections in the cat. Vet Microbiol 2005;105:1-7.

12. Litster $\mathrm{A}$, $\mathrm{Wu} \mathrm{CC}$, Leutenegger $\mathrm{CM}$. Detection of feline upper respiratory tract disease pathogens using a commercially available real-time PCR test. Vet J 2015;206:149-153.

13. Jung JY, Lee K, Choi EJ, Lee H, Moon BY, Kim HY, So B. Cat diseases diagnosed in Korea, 2015 2017. Korean J Vet Serv 2018;41:119-123.

14. Guo H, Miao Q, Zhu J, Yang Z, Liu G. Isolation and molecular characterization of a virulent systemic feline calicivirus isolated in China. Infect Genet Evol 2018;65:425429.

15. Di Martino B, Di Rocco C, Ceci C, Marsilio F. Characterization of a strain of feline calicivirus isolated from a dog faecal sample. Vet Microbiol 2009;139:52-57.

16. Caringella F, Elia G, Decaro N, Martella V, Lanave G, Varello K, Catella C, Diakoudi G, Carelli G, Colaianni ML, Bo S, Buonavoglia C. Feline calicivirus infection in cats with virulent systemic disease, Italy. Res Vet Sci 2019; 124:46-51.

17. Makino A, Shimojima M, Miyazawa T, Kato K, Tohya Y, Akashi H. Junctional adhesion molecule 1 is a functional receptor for feline calicivirus. J Virol 2006;80:4482-4490.

18. Prikhodko VG, Sandoval-Jaime C, Abente EJ, Bok K, Parra GI, Rogozin IB, Ostlund EN, Green KY, Sosnovtsev SV. Genetic characterization of feline calicivirus strains associated with varying disease manifestations during an outbreak season in Missouri (1995-1996). Virus Genes 2014;48:96-110.

19. Sun Y, Deng M, Peng Z, Hu R, Chen H, Wu B. Genetic and phylogenetic analysis of feline calicivirus isolates in China. Vet J 2017;220:24-27.

20. Glotova TI, Semenova OV, Nikonova AA, Glotov AG, Vyatkin YV, Bondar AA. [Isolation and phylogenetic analysis of feline calicivirus in Siberia]. Vopr Virusol 2018;63:268274.

21. Masubuchi K, Wakatsuki A, Iwamoto K, Takahashi T, Kokubu T, Shimizu M. Immunological and genetic characterization of feline caliciviruses used in the development of a new trivalent inactivated vaccine in Japan. J Vet Med Sci 2010;72:1189-1194.

22. Brunet S, Sigoillot-Claude C, Pialot D, Poulet H. Multiple correspondence analysis on amino acid properties within the variable region of the capsid protein shows differences between classical and virulent systemic feline calicivirus strains. Viruses 2019;11:1190. 